\title{
Effect of Steel Fibers on Properties of Modified Reactive Powder Concrete
}

\author{
Farah Saeed Rasheed, Khalil Ibrahim Aziz \\ Civil Engineering Department, University of Anbar, Ramadi, Iraq \\ Email address: \\ far17e102@uoanbar.edu.iq(F. S. Rasheed),k_ibraheem@yahoo.com (K. I. Aziz) \\ To cite this article: \\ Farah Saeed Rasheed, Khalil Ibrahim Aziz. Effect of Steel Fibers on Properties of Modified Reactive Powder Concrete. Engineering \\ Mathematics. Vol. 5, No. 1, 2021, pp. 1-6. doi: 10.11648/j.engmath.20210501.11
}

Received: January 9, 2021; Accepted: February 6, 2021; Published: March 30, 2021

\begin{abstract}
This paper provides the result of an investigation to use of crushed brick as aggregates which was collected from the demolition waste of buildings from different sites then crushed with (maximum size 10 mm) in producing modified reactive concrete $\mathrm{MRPC}$, which was presented by replacement the cementation binder (cement + silica fume) of original reactive powder concrete by $25 \%$ of crushed brick aggregates. The objective of this work is to study the effect of different type of steel fibers added in ratio $1 \%$ on the flowability and mechanical properties of reactive powder concrete and modified reactive powder concrete, which was micro steel fiber and hooked end steel fiber. The mechanical properties are examined by the tests of compressive strength, split tensile strength and flexural strength. The results showed that the compressive strength at 28 days of ORPC was $126.46 \mathrm{MPa}, 120 \mathrm{MPa}$ for the two types of steel fibers micro, hooked respectively. For the mix MRPC with micro, hooked the compressive strength at 28 days decreased by $1.53 \%$ and $1.15 \%$, compared with those of the RPC made with micro, hooked steel fibers. And observed from the experimental results that two mixtures (RPC and MRPC) with micro steel fiber gave higher mechanical properties compared with the hook end.
\end{abstract}

Keywords: Reactive Powder Concrete, MRPC, Crushed Brick Aggregate, Steel Fiber, Modified Reactive Powder Concrete

\section{Introduction}

Reactive Powder Concrete (RPC) is a special type of ultrahigh-performance concrete (UHPC), with high ductility and advanced mechanical properties. The term Reactive Powder Concrete has been utilized to describe a fiber-reinforced, superplasticizer, silica fume-cement mix with exceptionally water-cement ratio $(\mathrm{w} / \mathrm{c})$ and presence of very fine quartz sand with size $(0.15-0.40 \mathrm{~mm})$ rather than the coarse aggregate. The RPC is free of coarse aggregate in order to improve the performance, the microstructure, and homogeneity between the cement matrix of the RPC $[1,2]$.

Because of the utilization of exceptionally fine sand rather than ordinary coarse aggregate, the cement content in the RPC is as high as 800 to $1000 \mathrm{~kg} / \mathrm{m}^{3}$, silica fume (SF) content is regularly over $25 \%$ by the weight of cement. This will expand the production cost. Also, the high content of cement and SF can raise the hydration heat and which may be caused by shrinkage issues. To conquer these issues, some mineral admixtures were utilized to supplant concrete or decrease the SF amount [3]. Collepardi et al. (1997) [4] created modified reactive powder concrete (MRPC) by supplanting some portion of (or all) fine sand by $8 \mathrm{~mm}$ size crushed aggregate. Results demonstrate that the substitution of the fine ground quartz sand $(0.15-0.4 \mathrm{~mm})$ by an equivalent volume of wellgraded natural aggregate did not change the compressive strength of the RPC for same w/c ratio but flexural strength found to be lower. In order to enhance the fracture properties and improved tensile cracking, decreased crack width ductility, and post-cracking toughness, also and spacing fibers are incorporated in RPC even when the amount of added fiber is low [5-7].

Khalil.[8]investigated the Properties of modified RPC with crushed graded natural aggregate ( $\max$, size $12.5 \mathrm{~mm}$ ) which reinforced with different types of steel fibers (crimped and hooked) with percentages of volume fractions as $(0 \%, 0.5 \%$, and $1 \%$ ), results showed that the compressive strength of MRPC using crushed coarse aggregate was reached to 150 $\mathrm{MPa}$; This result contrasts with the model proposed by Richard and Cheyrezy, which states that the absence of 
coarse aggregates in RPC is the reason for their high compressive strength. Splitting tensile increased by $35 \%$ and $39 \%$, and flexural strength increased by about $25 \%$ and $29 \%$ for MRPC contains crimped and hooked steel fibers of volume fraction $1 \%$ respectively.

Hoagn et al [9] study effectiveness of steel fibers types mechanical properties of SCC using short straight steel fiber with aspect ratio 85 and long hooked ends steel fibers with aspect ratio 70 . Tests results showed that a reasonable combination of the two types of steel fibers types results of high flowability, the flexural strength of over $20 \mathrm{MPa}$ and compressive strength of over $150 \mathrm{MPa}$.

Zemei et al [10] study the influence of shaped of steel fibers. They adopted three types straight fibers, corrugated fibers, and hooked-end fiber, with three percentages $(0,1 \%$, $2 \%$, and $3 \%$ ) on some properties like workability, compressive strength, and flexural strengths of UHPC. They found that increasing fibers content and using deformed steel fibers led to gradually decrease in flowability of UHPC. A significant influence on compressive and flexural strengths was found. Incorporation of $3 \%$ straight fibers gave compressive and flexural strengths over 150 and $35 \mathrm{MPa}$ at 28 days ago. For 3\% hooked-end and corrugated steel fibers, the compressive strength increased by $48 \%$ and $59 \%$ compared to those with the same content of straight steel fibers. Zheng [11] showed that steel fibers with higher tensile strength and higher elastic modulus significantly improve the mechanical properties of concrete.

Wastes recycling and reusing is becoming one of the principal strategies for waste management particular interest to preserve natural sources [12]. Many researchers studied the effect of the recycled aggregates on the properties of concrete. To preserve natural aggregate sources as well as to reduce waste and waste storage using crushed bricks as coarse aggregates in concrete is of particular interest nowadays [13]. Mohamed, R, and Noha, M [14] studied the possibility of improving properties of concrete using waste clay brick as coarse aggregate with $100 \%$ replacement ratio by volume of natural coarse aggregate. The results showed improvement in hardened properties of recycled concrete by reducing the water/cement $(\mathrm{w} / \mathrm{c})$ ratio, increasing admixture ratio as a percentage of cement ratio and by using silica fume. $\mathrm{Ma}$ et al. [15] studied the UHPC with and without coarse aggregate and comparing his results with each other's. the result indicated that UHPC with coarse aggregate was homogenized mixing and easier during fluidized.

Debieb and Said. [16] investigated the using crushed brick as (coarse and fine aggregate) in concrete. Crushed brick aggregates were partially replaced by $(25,50,75$ and $100 \%)$ with either natural sand, coarse aggregates or both. The experimental work was including measured water absorption, water permeability, Porosity, and shrinkage. Compressive and flexural strengths were tested at 90 days of ages and compared with those of concrete made with natural aggregates. Results showed that it can be produced concrete with characteristics similar to those of natural aggregates concrete by including crushed bricks as coarse and fine aggregate.

Cachim [17] studied influence of replacement of natural coarse aggregate by using two types of crushed clay bricks aggregate and different water/cement $(w / c)$ ratios on the fresh and mechanical properties of concrete. when it was compared concrete produced with recycled aggregates with a reference concrete produced with natural limestone aggregates. The result showed the possibility of using producing concrete in different precast applications.

Aliabdo et al. [18] studied the possibility of utilizing of crushed clay brick produced from demolition waste as a powder and aggregate (fine and coarse) in concrete. The results show that the addition $25 \%$ of clay brick powder as percentages of cement weight reduced the volumes and numbers of pores in the microstructures of mortars and improves the compressive strength of mortar. There was a decrease in the compressive, splitting tensile strengths and modulus of elasticity for concrete content of crushed brick as aggregate as compared with natural limestone aggregate concrete.

Zhu et al. [19] studied the effect of waste of clay bricks powder and cement solids by partially replace silica fume or cement in reactive powder concrete. The replacement ratio effects on the flowability, strengths, and durability were studied in order to develop cost-saving and environmentallyfriendly reactive powder concrete (RPC). They found that the recycled powder can be used to replace partially the silica fume and/or cement in RPC.

Salahuddin et al, [20] investigated the effect of two types of recycled fine aggregates on the mechanical and durability properties including: compressive strength, tensile strength, flexural strength, water absorption and sorptivity of RPC. The recycled aggregates were obtained from demolished normal strength concrete RNSC and reactive powder concrete RRPC and were replaced by $(25 \%, 50 \%$ and $75 \%)$ from natural sand. The experimental result showed that the mechanical properties of RPC prepared with recycled aggregates increased up to $50 \%$ replacement, while durability performance gradually reduced with an increase in the recycled aggregate content.

\section{Experimental Program}

\subsection{Materials Properties}

In this investigation, Ordinary Portland cement (type I) with specific gravity 3.15 was used. and physical with chemical properties was comply with the Iraqi specification NO. 5/1984. Fine silica sand was supplied from Al-Ramadi Glass factory with max. the particle size of $600 \mu \mathrm{m}$ with specific gravity was 2.6 , sulfate content and absorption were within the limits of the Iraqi Specification No. 45/1984. Tap water was used for the production of RPC and MRPC and for curing. A grey colored densified silica fume and a superplasticizer commercially named MasterGlenium ${ }^{\circledR} 51$ obtained from BASF Chemicals Company were used to produce RPC and MRPC mixes and to enhance their 
properties.

Two types of steel fiber were used; hooked end steel fibers with an aspect ratio $(\mathrm{L} / \mathrm{d})$ of $55(\mathrm{~L}=30 \mathrm{~mm}, \mathrm{~d}=0.55 \mathrm{~mm})$, and micro steel fibers with an aspect ratio (L/d) of $81.25(\mathrm{~L}=13$ $\mathrm{mm}, \mathrm{d}=0.16 \mathrm{~mm}$ ), see table 1 .

Table 1. Properties of steel fiber.

\begin{tabular}{lllllll}
\hline Type of steel fiber & Length $(\mathbf{m m})$ & Diam $(\mathbf{m m})$ & Density $\mathbf{~ k g} / \mathbf{m}^{\mathbf{3}}$ & Tensile strength $(\mathbf{M P a})$ & Aspect ratio & Modulus of Elasticity $(\mathbf{G P A})$ \\
\hline micro & 13 & 0.16 & 7800 & 2600 & 81 \\
hook & 30 & 0.55 & 7860 & 1345 & 55 & 210 \\
\hline
\end{tabular}

Crushed brick with maximum (practical size of $10 \mathrm{~mm}$ ) was collected from the various demolished building sites in Al-Ramadi city were sorted, and classified into coarse aggregate as shown in figure 1, for MRPC mixes only. The specific gravity of Crushed brick is 2.17 . Table 2 show sieve analysis of producing crushed brick aggregate that conforms to Iraqi specification No. 45/1984 [21].

Table 2. Grading of crushed brick aggregate.

\begin{tabular}{lll}
\hline Sieve Size mm & $\begin{array}{l}\text { Cumulative } \\
\text { Passing \% }\end{array}$ & $\begin{array}{l}\text { Iraqi specification No. } \\
\mathbf{4 5} / \mathbf{1 9 8 4}[\mathbf{2 1}]\end{array}$ \\
\hline 12.5 & 100 & $95-100$ \\
9.5 & 96 & $85-100$ \\
4.75 & 24 & $0-25$ \\
2.36 & 4.3 & $0-5$ \\
Specific gravity=2.17 & & \\
\hline
\end{tabular}

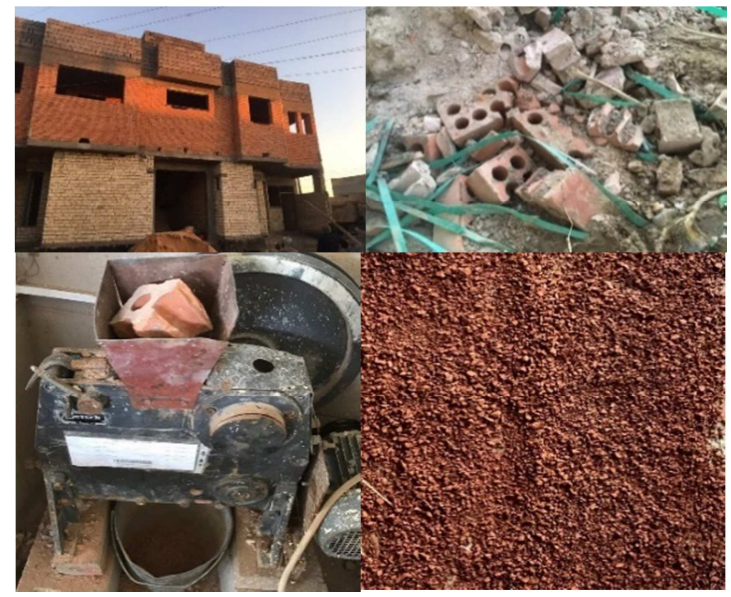

Figure 1. Crushed brick aggregate producing procedures.

\subsection{Mixes and Mixing Procedure}

Compressive, splitting strengths, flexural strengths, and flowability of Reactive Powder Concrete RPC with Modified Reactive Powder Concrete MRPC are compared for a different type of steel fibers (micro steel fiber and hooked end steel fiber) for each mix (RPC and MRPC) by volume fractions $1 \%$. Many mix proportions were tried to get maximum compressive strength and good workability according to (ASTM C1437, 2015) [22].

Table 3 gives a mix of proportions of RPC and MRPC mixes. For modified reactive powder concrete (MRPC) was used crushed brick aggregate as a partial replacement $(25 \%$ of cementation materials) of original reactive powder concrete (RPC). graded crushed brick aggregate prepares in the laboratory of Al-Anbar University.

The mixing procedures are as follow; Firstly, the silica fume powder was mixed in a dry state with the required quantity of cement for 5 minutes. Then, silica sand and crushed brick aggregate were loaded into the mixer and mixed for another 5 minutes. Mix (1/3) of superplasticizer with water and added to the mixer slowly for 5 minutes. The another of (2/3) of superplasticizer was added to the mixer and let go the mixer rotary for (3-5) minute. Finally, steel fibers were dispersed uniformly and mixed for an additional 5 minutes.

In this investigation flow table tested accordance to (ASTM C1437, 2015) is to be done to attain the required amount of mixing water for each concrete mixture, to reach the same workability level of concrete flow $(110 \% \pm 5)$. Figure 2 shows the measurement of consistency for RPC.

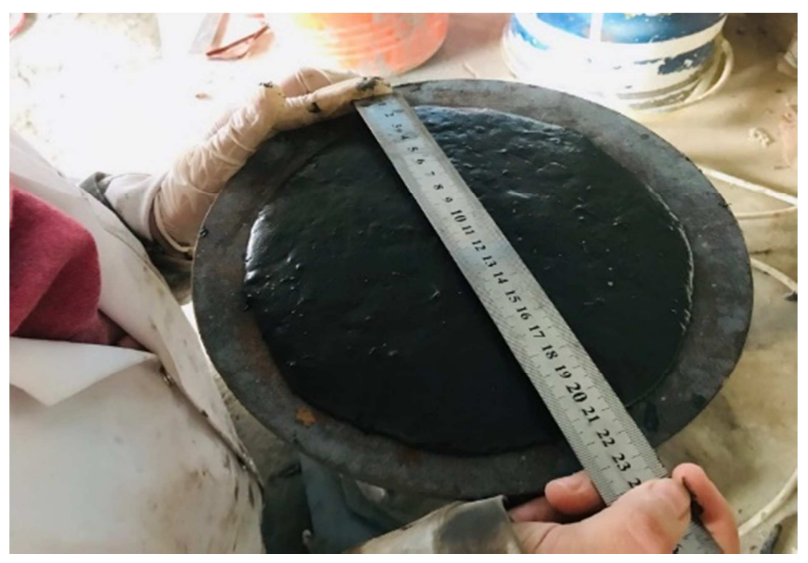

Figure 2. Flow Table test.

Table 3. Mix proportions of RPC and MRP $\left(\mathrm{kg} / \mathrm{m}^{3}\right)$.

\begin{tabular}{lll}
\hline Material & RPC & MRPC \\
\hline Cement (C) & 990 & 743 \\
Silica sand (S) & 990 & 990 \\
Crushed brick (B) & - & 302 \\
Silica fume (SF) & $218^{*}$ & $164^{*}$ \\
Super-plasticizer (SP) & $47^{* *}$ & $35.4^{* *}$ \\
Water (W) & 188 & 171 \\
W/C & 0.19 & 0.23 \\
Micro steel fiber (g) & 78 & 78 \\
Hooked steel fiber (h) & 78.6 & 78.6 \\
\hline
\end{tabular}

$* \mathrm{SF} / \mathrm{C}=22 \%, * * \mathrm{SP} /(\mathrm{C}+\mathrm{SF})=3.9 \%$

\subsection{Preparation and Tasting Specimen}

For Preparation and Testing of Specimens to reactive powder concrete and modified reactive powder concrete, the compressive strength test was made according to B. S: 1881 : part 116 [23] using cubic specimens $(100 * 100 * 100 \mathrm{~mm})$ using a digital testing machine of $2000 \mathrm{kN}$ capacity. 
The splitting tensile strength was performed according to ASTM C496-04 [24] using cylinders specimens $(100 \times 200 \mathrm{~mm})$. The flexural strength was determined by testing $(100 \times 100 \times 500) \mathrm{mm}$ prism specimens in conformity with ASTM C 78-02 [25].

All specimens were tested at of 28 days age and average of three specimens were adopted for each mix, except for flexural strength where two specimens were adopted.

\section{Experimental Results}

\subsection{Compressive Strength}

The results are shown in Figure 3 (a) show that the compressive strength of both RPC and MRPC for $100 \mathrm{~mm}$ cube specimens was slightly affected by steel fibers regards to its type. There is a slight decrease in compressive strength for MRPC about $1.5 \%$ and $1 \%$ with those of the RPC made with micro and hooked steel fibers respectively. It is also clear that the highest compressive strength recorded for the RPC and MRPC, which contain micro steel fiber than hooked end, and the lowest value of compressive strength was showed with mixes content hooked end steel fibers.

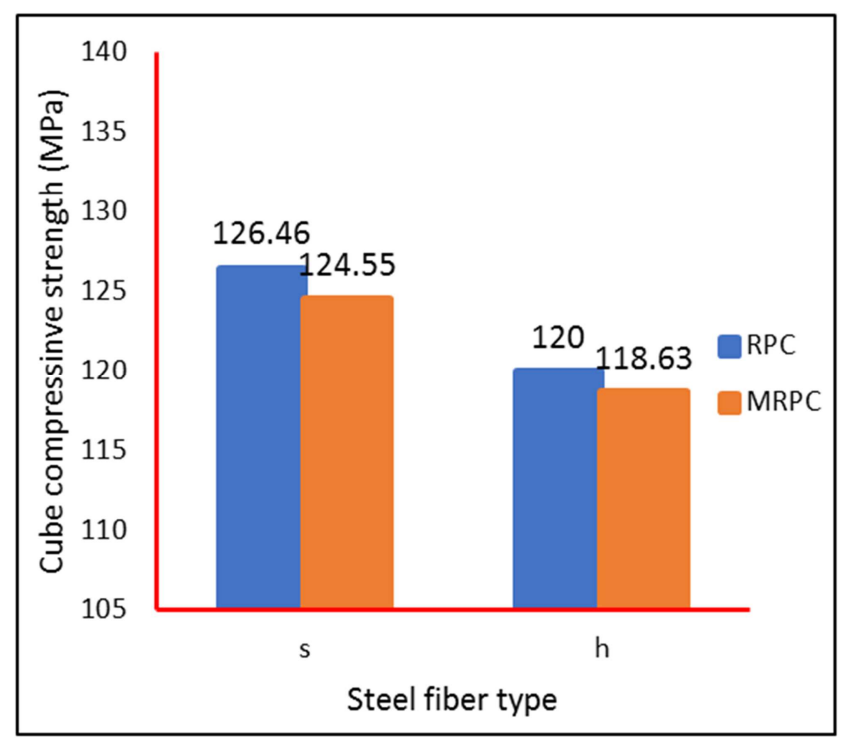

Figure 3. Effect of steel fiber type on Compressive strength for the cube (100) $m m$.

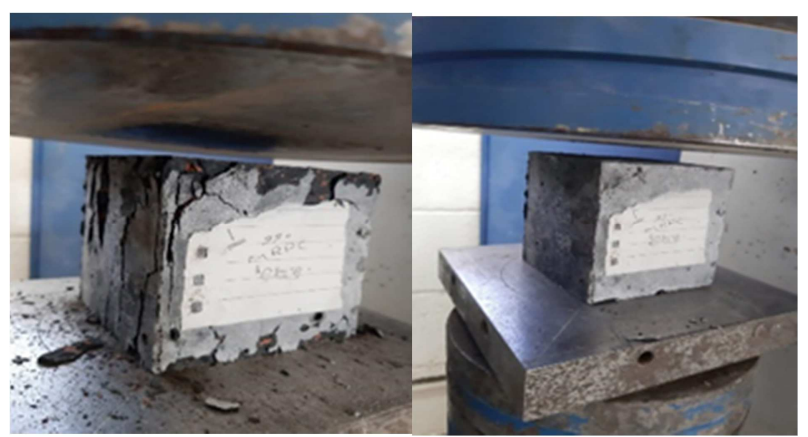

Figure 4. Mode of failure of compressive strength test.

\subsection{Splitting Strength}

As shown in Figure 5, the tensile strength values for the two mixtures of the two types of fibers are convergent. The ratio of tensile strength to MRPC decrease compared to RPC at about $10.7 \%$ for hook end steel fiber. It is also observed that the MRPC tensile strength with micro steel fiber is increased by approximately $2 \%$ compared to the RPC with the same type.

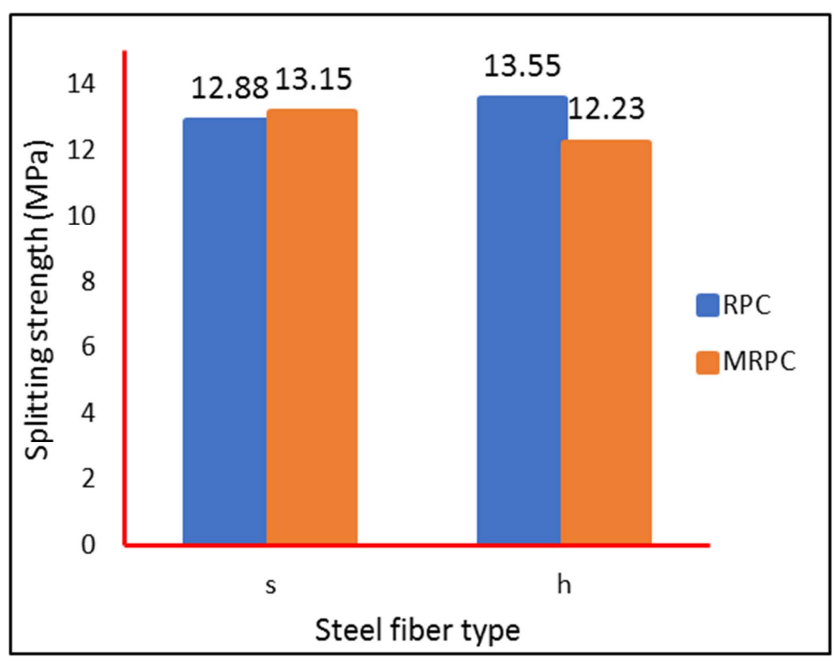

Figure 5. Effect of steel fiber type on splitting strength.

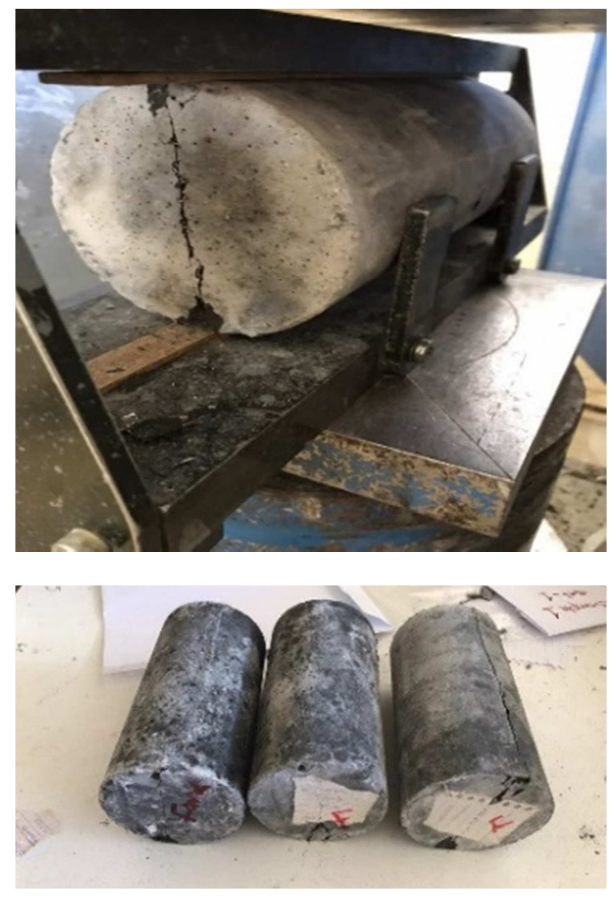

Figure 6. Mode of failure of splitting strength test.

\subsection{Flexural Strength}

As shown in Figure 7, the lowest flexural strength ratios were for MRPC mix containing hooked end by $51 \%$ compared with micro for the same mixture. And for RPC the lowest value for flexural strength was $11.5 \mathrm{MPa}$ for mixture with hooked end steel fiber which it is lower than mixture 
containing micro steel fiber by percentage $42.7 \%$.

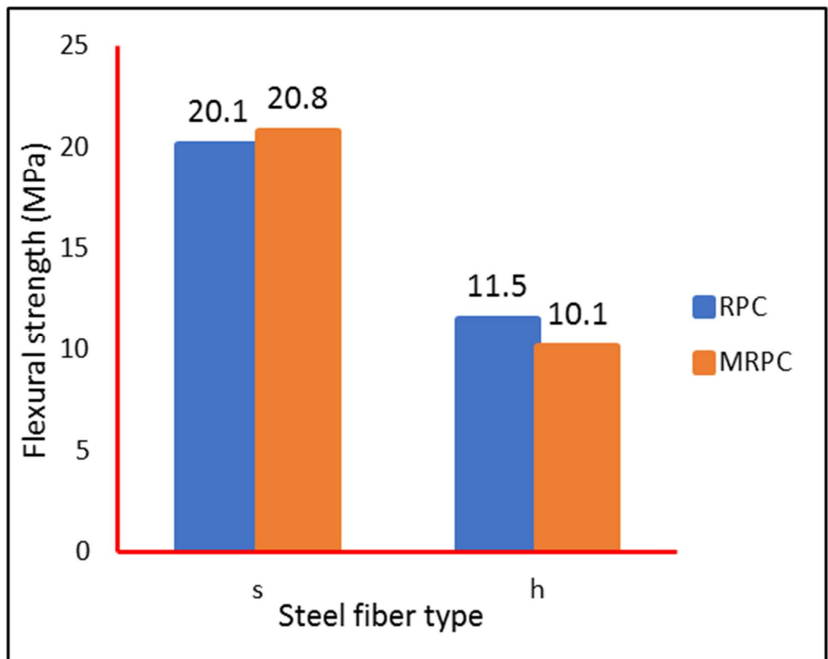

Figure 7. Effect of steel fiber type on flexural strength.

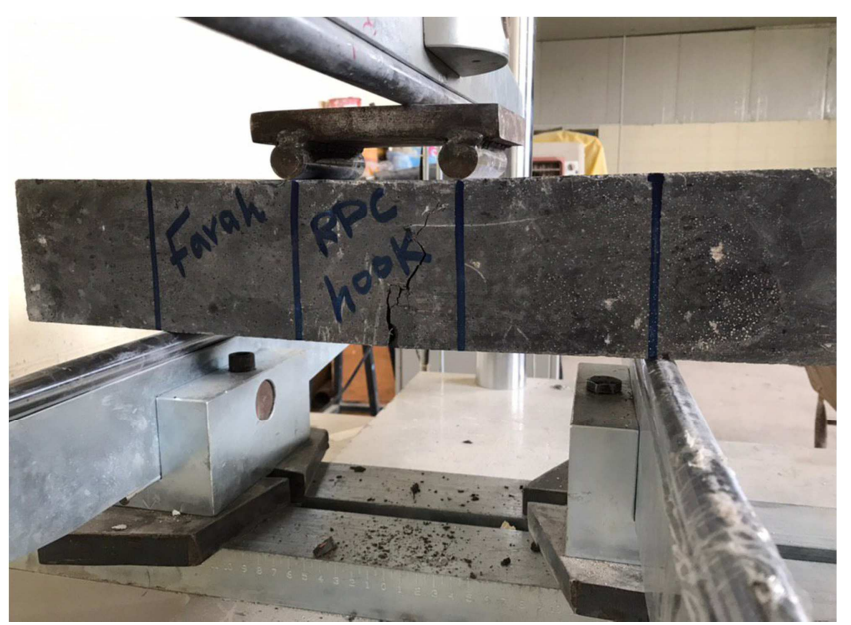

Figure 8. The failure mode of flexural strength test.

\section{Results Discussion}

It can be observed from the experimental results that two mixtures (RPC and MRPC) with micro steel fiber gave higher mechanical properties compared with the hook end. And also noted that the modified reactive powder concrete by including crushed bricks aggregate as partial replacement of cementation material for RPC the water to cement ratio $(\mathrm{W} / \mathrm{C})$ increase by $21 \%$ to reach the same workability of original RPC, as shown in figure 9. For the modified reactive powder concrete MRPC there was a very slightly decrease in compressive strength (100mm cube) by $1.53 \%$ and $1.15 \%$ with micro and hook steel fibers compared to RPC contains the same type, due to increasing $\mathrm{w} / \mathrm{c}$ ratio and reduction in the cementitious material. there was a little decrease in splitting and flexural strength for modified RPC with a mixture including hooked steel fibers, but there was small increase by $2 \%, 3 \%$ for splitting and flexural strength respectively, for the mixture contain micro steel fiber.

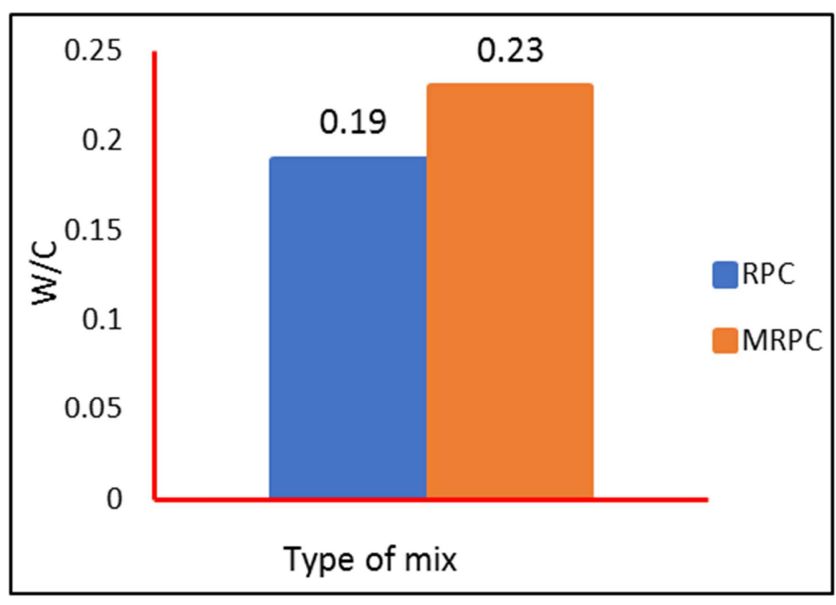

Figure 9. Effect of MRPC on w/c ratio.

\section{Conclusions}

The work introduced in this paper studied the effect of including crushed bricks aggregate as a partial replacement $25 \%$ of cementation material (cement and silica) for the original RPC. also, the influence of various types of steel fibers on the mechanical properties of reactive powder concrete and modified reactive powder concrete. different types of steel fibers have been presented into the RPC and MRPC at a volume fraction of $1 \%$. It can be concluded from the experimental results:

1. Reusing of waste and demolished bricks from various building sites in Al-Ramadi city as coarse aggregate with (max size $10 \mathrm{~mm}$ ) was good enough to partially replaced by ratio $25 \%$ of cementation materials for RPC, in term of acceptable performance of mechanical properties.

2. Replacing part of cementation material by crushed bricks aggregate the flowability of the mixture decrease so, the $\mathrm{w} / \mathrm{c}$ and $\mathrm{w} /(\mathrm{c}+\mathrm{sf})$ ratios were increased due to the reduction in the cementitious material. Due to that, the compressive strength was decreased.

3. The micro steel fiber has been showed the higher value of (compressive, splitting and flexural strength) for RPC and MRPC strengths, while that with hooked end showed the lowest corresponding values. This can be due to the different strength of the bound at fibermatrix, which depends on the shape of steel fiber.

4. Can be noticed with of changing of the steel fibers type from micro to hook the compressive strength decrease with percentage $(5.1 \%$ and $4.7 \%)$ for each mixture separately RPC, MRPC respectively.

5. The results show improves in split tensile strength of MRPC with micro steel fiber by $2 \%$ in compared with RPC, on contrast, mix MRPC showed high decrease by $9.7 \%$ with hook type of steel fiber. This was primarily due to high tensile strength for micro steel fiber than hooked end.

6. The flexural strength is highly affected by the changes in the type of steel fibers due to the different bond strength between the matrix and fibers type associated 
with fiber geometry. The micro steel fibers gave the flexural strength higher than hooked by $43 \%$ and $51 \%$ for RPC and MRPC respectively.

7. The flowability of RPC and MRPC was influenced by the type of steel fiber, where the mixture containing micro the flow was $(215 \mathrm{~mm})$, the flowability increase by $5 \%$ for mixes with hooked end fiber. This may be attributed to the lowest aspect ratio and high length (30mm) compared to micro steel fiber with length $13 \mathrm{~mm}$.

\section{References}

[1] P. Richard and M. Cheyrezy, "Composition of reactive powder concrete," Cem. Concr. Res., vol. 25, no. 7, pp. 1501-1511, 1995.

[2] P. Richard and M. Cheyrezy, "Reactive powder concretes with high ductility and 200-800 MPa tensile strength," in San Francisco: ACI Spring Convention, SP, 1994, pp. 124-144.

[3] H. Yazici, M. Y. Yardimci, S. Aydin, and A. Ş. Karabulut, "Mechanical properties of reactive powder concrete containing mineral admixtures under different curing regimes," Constr. Build. Mater., vol. 23, no. 3, 2009.

[4] S. Collepardi, L. Coppola, R. Troli, and M. Collepardi, "Mechanical properties of modified reactive powder concrete," ACI Spec. Publ., vol. 173, pp. 1-22, 1997.

[5] T. Noshiravani and E. Brühwiler, "Experimental investigation on reinforced ultra-high-performance fiber-reinforced concrete composite beams subjected to combined bending and shear," ACI Struct. J., vol. 110, no. ARTICLE, pp. 251-261, 2013.

[6] J. Susetyo, P. Gauvreau, and F. J. Vecchio, "Effectiveness of Steel Fiber as Minimum Shear Reinforcement.," ACI Struct. J., vol. 108 , no. 4, 2011.

[7] K. Wille, A. E. Naaman, and S. El-Tawil, "Optimizing ultrahigh performance fiber-reinforced concrete," Concr. Int., vol. 33 , no. 9 , pp. 35-41, 2011.

[8] W. I. Khalil, "Some Properties of Modified Reactive Powder Concrete," J. Eng. Dev., vol. 16, no. 4, pp. 66-87, 2012.

[9] K. Hoang, H. Phat, L. Hien, and N. Chanh, "Influence of types of steel fiber on properties of ultra high performance concrete," in The 3rd AFC International Conference ACG/VCA, 2008, pp. 347-355.

[10] Z. Wu, C. Shi, W. He, and L. Wu, "Effects of steel fiber content and shape on mechanical properties of ultra high performance concrete," Constr. Build. Mater., vol. 103, pp. 814, 2016.
[11] Z. Zheng and D. Feldman, "Synthetic fibre-reinforced concrete," Prog. Polym. Sci., vol. 20, no. 2, pp. 185-210, 1995.

[12] M. Safiuddin, M. Z. Jumaat, M. A. Salam, M. S. Islam, and R. Hashim, "Utilization of solid wastes in construction materials," Int. J. Phys. Sci., vol. 5, no. 13, pp. 1952-1963, 2010.

[13] A. Devenny and F. M. Khalaf, "Use of crushed brick as coarse aggregate in concrete," Mason. Int., vol. 12, no. 3, pp. 81-84, 1999.

[14] C. Brick, "Improvement Properties of Recycle Concrete using Clay Brick as a Coarse Aggregate," vol. 4, no. 1, pp. 119-127, 2014.

[15] J. Ma, M. Orgass, F. Dehn, D. Schmidt, and N. V Tue, "Comparative investigations on ultra-high performance concrete with and without coarse aggregates," in International Symposium on Ultra High Performance Concrete, Kassel, Germany, 2004, pp. 205-212.

[16] F. Debieb and S. Kenai, "The use of coarse and fine crushed bricks as aggregate in concrete," Constr. Build. Mater., vol. 22, no. 5, pp. 886-893, 2008.

[17] P. B. Cachim, "Mechanical properties of brick aggregate concrete," Constr. Build. Mater., vol. 23, no. 3, pp. 1292-1297, 2009.

[18] A. A. Aliabdo, A. E. M. Abd-Elmoaty, and H. H. Hassan, "Utilization of crushed clay brick in concrete industry," Alexandria Eng. J., vol. 53, no. 1, pp. 151-168, 2014.

[19] P. Zhu, X. Mao, W. Qu, Z. Li, and Z. J. Ma, "Investigation of using recycled powder from waste of clay bricks and cement solids in reactive powder concrete," Constr. Build. Mater., vol. $113,2016$.

[20] Salahuddin, H., Qureshi, L. A., Nawaz, A., and Raza, S. S., 2020. Effect of recycled fine aggregates on the performance of Reactive Powder Concrete. Construction and Building Materials, 243, p. 118223.

[21] I. Specification, "No. 45/1984,“,” Aggreg. from Nat. sources Concr. Constr., 1984.

[22] C. ASTM, "Standard test method for flow of hydraulic cement mortar," C 1437, 2007.

[23] B. S. 1881, part 116, "Method of Determination of Compressive Strength of Concrete Cubes", British Standards Institution, 1989, 3pp.

[24] ASTM C496/C496M-04, "Standard Test Method for Splitting Tensile Strength of Cylindrical Concrete Specimens", Vol. 04.02, 2004, 5pp.

[25] ASTM C78-02, "Standard Test Method for Flexural Strength of Hydraulic-Cement Mortars", Vol. 04.02, 2002, 6pp. 